Article

\title{
Immobilization of Arabidopsis thaliana Hydroxynitrile Lyase (AtHNL) on EziG Opal
}

\author{
José Coloma ${ }^{1,2}$, Tim Lugtenburg ${ }^{1}$, Muhammad Afendi ${ }^{1}$, Mattia Lazzarotto ${ }^{1,3}$, Paula Bracco ${ }^{1}$, \\ Peter-Leon Hagedoorn ${ }^{1}$ (D), Lucia Gardossi ${ }^{3}$ (D) and Ulf Hanefeld ${ }^{1, *}$ (D) \\ 1 Biokatalyse, Afdeling Biotechnologie, Technische Universiteit Delft, Van der Maasweg 9, 2629 HZ Delft, \\ The Netherlands; J.L.ColomaHurel@tudelft.nl (J.C.); t.g.lugtenburg@tudelft.nl (T.L.); \\ MuhammadFarhanbinMuhammadAfendi@student.tudelft.nl (M.A.); mattia.lazzarotto@uni-graz.at (M.L.); \\ paulabracco@gmail.com (P.B.); P.L.Hagedoorn@tudelft.nl (P.-L.H.) \\ 2 Facultad de Ciencias Agropecuarias, Ingeniería Agroindustrial, Universidad Laica Eloy Alfaro de Manabí, \\ Avenida Circunvalación s/n, Manta 13-05-2732, Ecuador \\ 3 Dipartimento di Scienze Chimiche e Farmaceutiche, Università degli Studi di Trieste, Via Licio Giorgieri 1, \\ 34127 Trieste, Italy; gardossi@units.it \\ * Correspondence: u.hanefeld@tudelft.nl; Tel.: +31-15-278-9304
}

Received: 17 July 2020; Accepted: 5 August 2020; Published: 8 August 2020

check for updates

\begin{abstract}
Arabidopsis thaliana hydroxynitrile lyase (AtHNL) catalyzes the selective synthesis of $(R)$-cyanohydrins. This enzyme is unstable under acidic conditions, therefore its immobilization is necessary for the synthesis of enantiopure cyanohydrins. EziG Opal is a controlled porosity glass material for the immobilization of His-tagged enzymes. The immobilization of $\mathrm{His}_{6}$-tagged AtHNL on EziG Opal was optimized for higher enzyme stability and tested for the synthesis of $(R)$-mandelonitrile in batch and continuous flow systems. AtHNL-EziG Opal achieved 95\% of conversion after $30 \mathrm{~min}$ of reaction time in batch and it was recycled up to eight times with a final conversion of $80 \%$ and excellent enantioselectivity. The EziG Opal carrier catalyzed the racemic background reaction; however, the high enantioselectivity observed in the recycling study demonstrated that this was efficiently suppressed by using citrate/phosphate buffer saturated methyl-tert-butylether (MTBE) $\mathrm{pH} 5$ as reaction medium. The continuous flow system achieved $96 \%$ of conversion and excellent

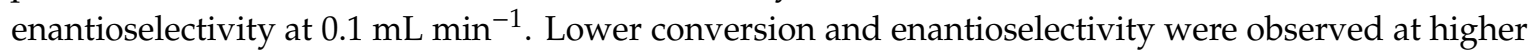
flow rates. The specific rate of AtHNL-EziG Opal in flow was $0.26 \mathrm{~mol} \mathrm{~h}^{-1} \mathrm{~g}_{\text {enzyme }}{ }^{-1}$ at $0.1 \mathrm{~mL} \mathrm{~min}^{-1}$ and $96 \%$ of conversion whereas in batch, the immobilized enzyme displayed a specific rate of $0.51 \mathrm{~mol} \mathrm{~h}^{-1} \mathrm{~g}_{\text {enzyme }}{ }^{-1}$ after $30 \mathrm{~min}$ of reaction time at a similar level of conversion. However, in terms of productivity the continuous flow system proved to be almost four times more productive than the batch approach, displaying a space-time-yield (STY) of $690 \mathrm{~mol}_{\text {product }} \mathrm{h}^{-1} \mathrm{~L}^{-1} \mathrm{~g}_{\text {enzyme }}{ }^{-1}$ compared to 187 mol $_{\text {product }} \mathrm{h}^{-1} \mathrm{~L}^{-1} \mathrm{~g}_{\text {enzyme }}{ }^{-1}$ achieved with the batch system.
\end{abstract}

Keywords: Arabidopsis thaliana; hydroxynitrile lyase; oxynitrilase; His-tag; immobilization; batch; continuous flow

\section{Introduction}

Hydroxynitrile lyases (HNLs) are enzymes that catalyze the synthesis of enantiopure cyanohydrins (Scheme 1), known building blocks for the production of fine chemicals, pharmaceuticals and cosmetics [1-4]. HNL catalyzed reactions are faced with two problems, the chemical formation of racemic cyanohydrins and product racemization due to the reaction equilibrium [5]. These limitations can be overcome by performing the reactions in buffer saturated organic solvent and adjusting the $\mathrm{pH}$ to the lower limit accepted for HNLs $[5,6]$. These conditions are not the natural environment of HNLs, as they have to be stabilized for instance by immobilization on a suitable carrier. 


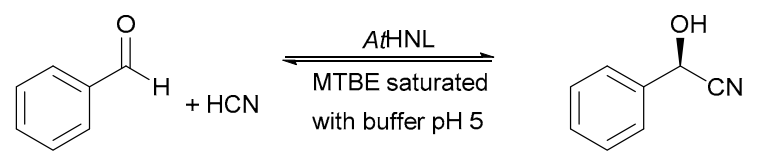

Scheme 1. AtHNL catalyzed hydrocyanation of benzaldehyde yielding (R)-mandelonitrile.

Improved stability, activity and selectivity of immobilized enzymes have been reported earlier $[7,8]$. In addition, immobilization enables the increase of enzyme loading and facilitates recycling and downstream processing. To achieve the beneficial aspects mentioned before, the characteristics of enzyme and carrier must be considered. However, there is not a general method to immobilize an enzyme and its feasibility must be determined experimentally $[9,10]$.

Immobilized metal ion chromatography (IMAC) is a widely used technique for the purification and immobilization of His-tagged enzymes. The enzyme immobilization is based on the affinity of divalent metal ions such as $\mathrm{Zn}^{2+}, \mathrm{Cu}^{2+}, \mathrm{Ni}^{2+}$ or $\mathrm{Co}^{2+}$ to the imidazole ring of histidines. Chelated $\mathrm{Ni}^{2+}$ on nitrilotriacetic acid (Ni-NTA) has turned out to be the most effective combination for the purification of His-tagged proteins [11]. However, nickel induced genotoxicity, carcinogenicity and immunotoxicity has been reported [12]. Hence, the development of a carrier with a non-toxic metal ion is highly desirable.

A new set of carriers (EziG, provided by EnginZyme AB, Stockholm, Sweden) containing non-toxic $\mathrm{Fe}^{3+}\left(>10 \mu \mathrm{mol} \mathrm{g}{ }^{-1}\right)$ on its surface has been developed for the immobilization of His-tagged enzymes. These materials have a core made of controlled porosity glass (CPG) particles facilitating mass transfer from reactants and products to the material due to its interconnecting pore structure (circa $1.8 \mathrm{~mL} \mathrm{~g}^{-1}$ ). In addition, its non-compressible non-swelling nature is an advantage compared to NTA agarose. The porous surface can be coated with an organic polymer to tailor carriers with different hydrophobic characteristics such as EziG Opal (hydrophilic), EziG Coral (hydrophobic) and EziG Amber (semi-hydrophobic). Given the hydrophilic surface of $\mathrm{His}_{6}$-tagged AtHNL [13], its immobilization was performed on EziG Opal. Moreover, EziG Opal has been found to be suitable for reactions in organic solvents [14], a crucial property to enable the synthesis of enantiopure cyanohydrins together with low $\mathrm{pH}$ required in the reaction medium [5,15-19].

Some successful studies with different immobilized enzymes on EziG carriers have been reported earlier. An $\omega$-transaminase was active in methyl-tert-butylether (MTBE) and a Baeyer-Villiger monooxygenase (BVMO) together with two cofactor-regenerating enzymes displayed increased stability [14]. An $\omega$-transaminase from Arthrobacter sp. (AsR- $\omega T$ TA) on EziG Amber was highly stable in batch and continuous flow systems [20]. On the other hand, when an old yellow enzyme (OYE) was immobilized on EziG Opal, poor recyclability was observed, and the initial conversion dropped to 56\% after two reaction cycles [21]. The loss of activity of OYE was assumed to be due to enzyme leaching and/or deactivation of the enzyme. Likewise, the enzyme arylmalonate decarboxylase (AMDase) presented a significant loss of activity during recycling studies on all EziG carriers [22]. The loss of activity of AMDase activity on EziG carriers was explained to be due to enzyme leaching because the of the lower strength of the coordinate bond and due to local $\mathrm{pH}$ changes by the acidic product of the reaction.

Enzyme catalyzed reactions in flow are gaining attention due to improved productivity, easier downstream processing and efficiency of scale-up compared to batch systems. Reduced reaction times and enhanced selectivity are reported benefits of performing reactions in flow [23-26]. On top of all these benefits mentioned before, continuous flow reactions allow to optimize resource utilization, reduce reaction volumes and consequently achieve waste reductions and lower energy consumption [27]. Furthermore, they allow handling of toxic and reactive reagents such as cyanide [28] in a safer manner.

The aim of this study is to immobilize AtHNL on EziG Opal based on the His-tag/ $/ \mathrm{Fe}^{3+}$ affinity and compare its performance for the synthesis of $(R)$-mandelonitrile with the earlier reported successful immobilization of $A t H N L$ on Celite by adsorption [15]. Important parameters such as stability, specific rate and productivity were investigated in batch and flow systems. 


\section{Results and Discussion}

AtHNL was recombinantly produced with a $\mathrm{His}_{6}$-tag to enable its purification and immobilization by metal-ion affinity. It was successfully overexpressed in E. coli BL21(DE3) and purified displaying a specific activity of $136.5 \pm 3.2 \mathrm{U} \mathrm{mg}^{-1}$. At HNL was purified prior to its immobilization to avoid binding of other proteins with affinity to the EziG Opal carrier.

\subsection{Batch Reactions}

All batch reactions were performed with AtHNL-EziG Opal tightly packed into tea bags. Earlier research revealed that while the material of the bags had no influence on the conversion and enantioselectivity, it was essential to pack the bags tightly $[16,18,29]$. A magnetic stirrer was attached to the tea bag to enable the rotation of the immobilized enzyme and stirrer simultaneously. This set up avoids mechanical attrition of the carrier caused by the stirrer and facilitates the manipulation of the immobilized enzyme for recyclability studies without any loss of enzyme material. A leaching assay showed that AtHNL did not leach from EziG Opal carrier to the reaction medium (Figure S1). Similarly, no leaching had been reported previously for hydrocyanation reactions catalyzed by immobilized HNLs on siliceous carriers in general and AtHNL specifically [15,16,18,29].

Once it was established that EziG Opal is a suitable carrier for the immobilization of AtHNL (Figure S1), preliminary time studies using different enzyme loadings of AtHNL-EziG Opal for the synthesis of $(R)$-mandelonitrile were performed (Figure 1). The different enzyme loadings showed a huge difference in conversion and enantiopurity during four hours of reaction time. In these preliminary experiments, AtHNL was immobilized on EziG Opal by incubating an enzyme solution with the carrier in an orbital shaker (see Section 3.7 for details). The rotation enabled the enzyme to bind to the carrier but some precipitation was observed and it might explain the results in Figure 1. On the other hand, an earlier report [15] showed that $A t \mathrm{HNL}$ on Celite R-633 displayed near complete conversion and excellent enantioselectivity after $45 \mathrm{~min}$ using $5 \mathrm{mg} \mathrm{mL}^{-1}$ (circa $400 \mathrm{U}$ ) and MTBE saturated with citrate/phosphate buffer $\mathrm{pH}$ 5.5. The enzyme was immobilized by adsorption in that study. In addition, the successful immobilizations of Prunus amydalus HNL (PaHNL) [16], Manihot esculenta HNL (MeHNL) [18] and Granulicella tundricola HNL (GtHNL) [29] on Celite were also performed by adsorbing all the enzyme solution into the carrier until saturation, which means that the enzyme solution is completely adsorbed into the carrier, just like in the case of Celite. All these results suggest that the immobilization of $A t \mathrm{HNL}$ on EziG Opal had to be optimized.

In order to optimize the immobilization of $A t \mathrm{HNL}$ on EziG Opal, the enzyme was immobilized by either incubating an enzyme solution in an orbital shaker or by adding it dropwise to EziG Opal carrier in such a way that the carrier absorbs the enzyme solution completely, as in the case of Celite $[15,16,18,29]$. Additionally, the effect of drying AtHNL-EziG Opal, which might influence the enzyme performance, was investigated. For this, AtHNL-EziG Opal was used either immediately after its immobilization (wet $A t$ HNL-EziG Opal) or after $16 \mathrm{~h}$ of drying under vacuum in a desiccator over silica gel. Figure 2 shows the effect of drying AtHNL-EziG Opal and the immobilization method on the bioconversions. The immobilization of $A t \mathrm{HNL}$ in an orbital shaker with subsequent drying had a large negative impact on the conversion and enantioselectivity for the synthesis of $(R)$-mandelonitrile (Figure 2, dotted line and diamonds). The reaction catalyzed by wet AtHNL-EziG Opal (Figure 2, dashed line and triangles) proceeded faster and with improved enantioselectivity ( $92 \%$ of conversion and $92 \%$ of enantioselectivity) as compared to the dried AtHNL-EziG Opal ( $43 \%$ of conversion and $63 \%$ of enantioselectivity). As drying proved to have a negative impact on the enzyme activity and enantioselectivity, two reactions with wet AtHNL-EziG Opal immobilized by either incubation in an orbital shaker or adsorption were performed. A faster reaction was observed when the enzyme was immobilized by adsorption (Figure 2, continuous line and crosses), comparable to the results with Celite [15]. Similar conversion (circa 95\% in both cases) was obtained after $4 \mathrm{~h}$ of reaction time, but enantioselectivity was slightly better for the enzyme immobilized by adsorption $(96 \% e e)$ as compared to the enzyme immobilized by incubation $(92 \% e e)$. Surprisingly, the effect of drying on the 
reaction rate was negligible for AtHNL immobilized by adsorption on EziG Opal (Figure 2, dashed line and dots). Conversions of circa $96 \%$ were obtained for both dried and non-dried AtHNL-EziG Opal immobilized by adsorption within $30 \mathrm{~min}$ and little change was observed in the following $3.5 \mathrm{~h}$. A possible explanation is that the enzyme is immediately stabilized right after its adsorption into the pores of the carrier, thus it is capable to endure the mechanical stress caused by the orbital shaker as well as the drying.

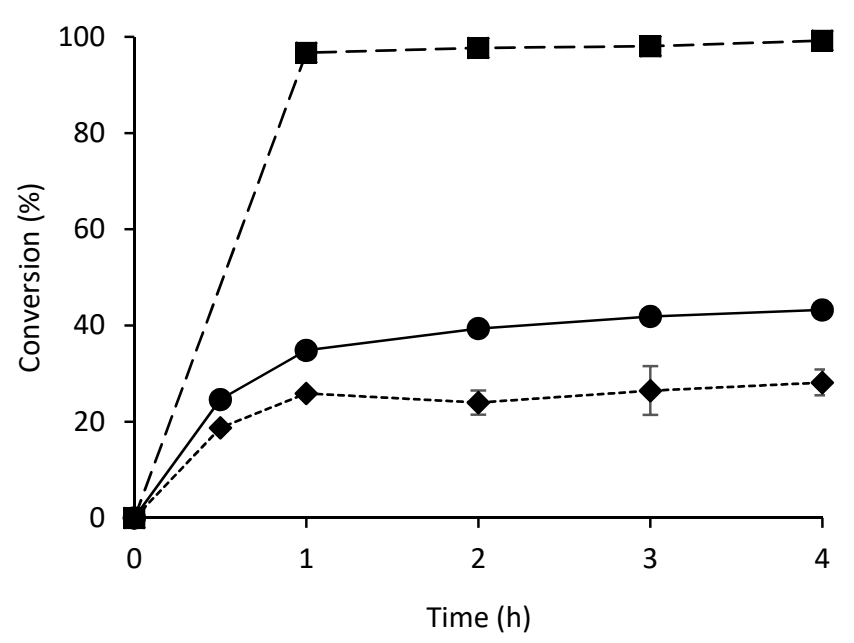

Figure 1. Synthesis of (R)-mandelonitrile using different enzyme loadings. Immobilization was performed by incubating enzyme and carrier in an orbital shaker and subsequent drying. Dashed line and squares $\left(20 \mathrm{U} \mathrm{mg}^{-1}\right.$, final $\left.e e=99 \%\right)$, solid line and dots $\left(10 \mathrm{U} \mathrm{mg}^{-1}\right.$, final $\left.e e=63 \%\right)$ and dotted line and diamonds ( $5 \mathrm{U} \mathrm{mg}^{-1}$, final $e e=23 \%$ ). Conditions: Ratio benzaldehyde: $\mathrm{HCN}$ in citrate/phosphate buffered MTBE, pH 5, 1:4, benzaldehyde (100 $\mu \mathrm{L}, 1 \mathrm{mmol}), 2 \mathrm{~mL} \mathrm{HCN}$ solution in citrate/phosphate buffered MTBE (1.5-2 M) pH 5, $27.5 \mu \mathrm{L}$ (0.1 mmol) 1,3,5-triisopropylbenzene as internal standard (I.S.) and a teabag filled with AtHNL immobilized on $60 \mathrm{mg}$ EziG Opal. The reaction was stirred at $900 \mathrm{rpm}$ at room temperature. Error bars correspond to the standard deviation of duplicates $(n=2)$ HPLC samples of the single experiment.

The lower conversions observed when the enzyme was immobilized by incubation might be explained by the loss of the AtHNL dimeric structure caused by the rotation in an orbital shaker. In fact, some precipitation was observed after the incubation time. Earlier reports have shown that the enzyme stability is enhanced by higher oligomeric states [30]. Indeed, the ability of $\mathrm{MeHNL}$ to form tetramers in solution whereas AtHNL forms dimers, explained the superior stability to higher temperatures and lower $\mathrm{pH}$-values observed for $\mathrm{MeHNL}$ as compared to AtHNL [31]. Similarly, $M e \mathrm{HNL}$ proved to be more stable than dimeric Hevea brasiliensis HNL (HbHNL) for the synthesis of $(S)$-mandelonitrile in a monolith microreactor [17]. The formation of $\mathrm{MeHNL}$ tetrameric structures was attributed as the most likely reason for its higher stability.

Earlier studies [15] demonstrate a significant influence of the water content on enzyme activity of immobilized AtHNL on Celite R-633, indicating that the minimal water content of AtHNL-Celite for retaining enzymatic activity is $10 \%(w / w)$ of the immobilized enzyme. Additionally, the stability of $\mathrm{MeHNL}$ as CLEA or immobilized on Celite R-633 is highly dependent on the water entrapped in the carrier [18,32]. This effect can be ruled out here as buffer saturated MTBE was used as solvent.

Silica carriers, such as EziG Opal, are known to catalyze the chemical racemic background reaction [15-19,33,34] (Figures S2 and S3). However, the enantioselectivities achieved here in batch reactions under the optimized immobilization condition demonstrated the efficient suppression of this undesired reaction. 


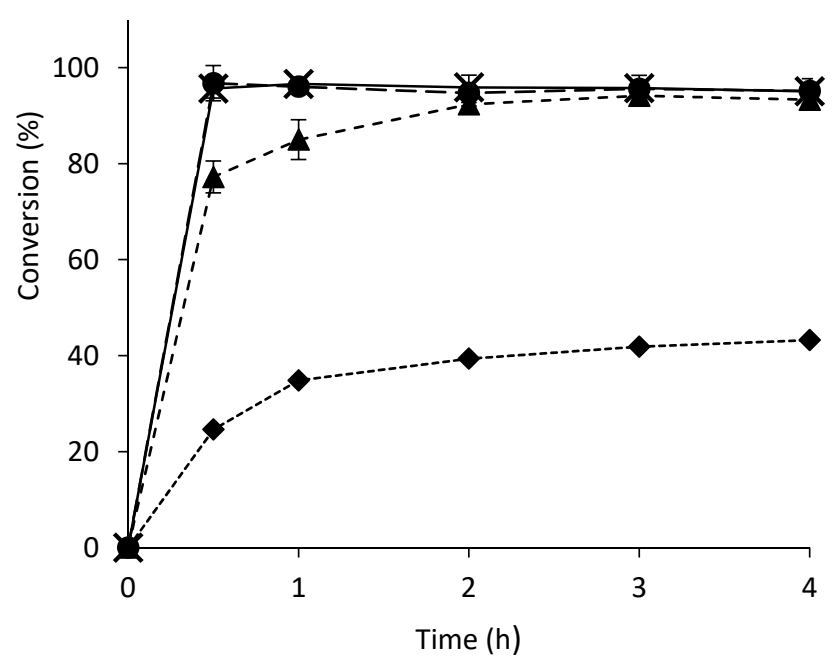

Figure 2. Effect of immobilization method and drying on the synthesis of $(R)$-mandelonitrile. Continuous line and crosses is the reaction with wet AtHNL-EziG Opal (adsorption), final $e e=96.2 \%$; dashed line and dots is the reaction with dried AtHNL-EziG Opal (adsorption) final $e e=93.8 \%$; dashed line and triangles is the reaction with wet AtHNL-EziG Opal (incubation in orbital shaker), final $e e=92.3 \%$ and dotted line and diamonds is the reaction with dried AtHNL-EziG Opal (incubation in orbital shaker), final $e e=63.3 \%$. Conditions: Ratio benzaldehyde:HCN in citrate/phosphate buffered MTBE, pH 5, 1:4, benzaldehyde (100 $\mu \mathrm{L}, 1 \mathrm{mmol}), 2 \mathrm{~mL} \mathrm{HCN}$ solution in citrate/phosphate buffered MTBE (1.5-2 M) pH 5, $27.5 \mu \mathrm{L}$ (0.1 mmol) 1,3,5-triisopropylbenzene as I.S. and a teabag filled with AtHNL immobilized on $60 \mathrm{mg}$ EziG Opal. All reactions were performed with enzyme loading of $10 \mathrm{U} \mathrm{mg}^{-1}$ and the mol ratio of monomeric $A t \mathrm{HNL}: \mathrm{Fe}^{3+}$ was 1:5. The reaction was stirred at $900 \mathrm{rpm}$ at room temperature. Error bars of wet AtHNL- EziG Opal (adsorption), wet AtHNL-EziG Opal (incubation) and dried AtHNL-EziG Opal (incubation) correspond to the standard deviation of duplicate $(n=2)$ HPLC samples of the single experiment. Error bars of the reaction with dried AtHNL-EziG Opal (adsorption) correspond to the standard deviation of triplicate $(n=3)$ HPLC samples of the single experiment.

In addition to enzymatic activity and enantioselectivity, the stability of immobilized enzymes is crucial in biocatalytic applications. Indeed, one of the main objectives of enzyme immobilization is the potential for recycling the biocatalyst $[4,6,35]$. Since the best results for the synthesis of (R)-mandelonitrile were obtained with wet AtHNL-EziG Opal $\left(10 \mathrm{U} \mathrm{mg}^{-1}\right)$ immobilized by adsorption, a recyclability study was performed under these conditions (Figure 3). In order to avoid enzyme overloading on the carrier which might lead to misinterpretations in the recyclability study, the mol ratio of monomeric At $\mathrm{HNL}: \mathrm{Fe}^{3+}$ used was 1:5, thus ensuring any enzyme deactivation is visible during the reaction cycles. Near complete conversion and excellent enantioselectivity $(>99 \%)$ were observed during 7 cycles. When $10 \mathrm{U} \mathrm{mg}^{-1}$ of the enzyme were immobilized by incubation in an orbital shaker and subsequent drying, the recycling was unsuccessful (data not shown), whereas an enzyme loading of $20 \mathrm{U} \mathrm{mg}^{-1}$ led to a biocatalyst that could be recycled five cycles (Figure S4).

Figure 3 shows that EziG Opal enables to recycle AtHNL over several cycles with good conversion and enantioselectivity under the conditions of this study; accomplishing one of the main objectives of enzyme immobilization. Similarly, AtHNL on Celite displayed good conversion $(>95 \%)$ and excellent enantioselectivity $(>98 \% e e$ ) during five consecutive reaction cycles [15]. Also, the successful recyclability of $\omega$-transaminase from Arthrobacter sp. (AsR- $\omega \mathrm{TA}$ ) immobilized on EziG Amber (semi hydrophobic polymer surface) has been reported [20]. The immobilized AsR-wTA (10 mg, $10 \%$ enzyme loading, $\mathrm{w} \mathrm{w}^{-1}$ ) was used for the kinetic resolution of $r a c-\alpha$-methylbenzylamine during 16 consecutive reaction cycles with excellent conversion and enantioselectivity. On the other hand, poor recyclability was recently reported [21] for the bioreduction of $\alpha$-methyl-trans-cinnamaldehyde with a co-immobilized preparation of old yellow enzyme 3 (OYE3) and glucose dehydrogenase (GDH) 
on EziG Opal (OYE3/GDH- EziG Opal). The conversion dropped to $56 \%$ after only two reaction cycles. However, it is worthy to mention that after 11 cycles (almost no conversion) the addition of GDH increased the conversion up to $30 \%$ suggesting that GDH was gradually deactivated or leached from the carrier over the reaction cycles. Also, the synthesis of enantiopure (S)-arylpropinate using arylmalonate decarboxylase (AMDase) immobilized on three EziG carriers with different surface hydrophobicity has been reported [22]. The best activity was obtained with the hydrophilic carrier (EziG Opal). Unfortunately, the enzyme was nearly fully deactivated after the second reaction cycle for the three EziG carriers. This significant loss of enzymatic activity was attributed to enzyme leaching or local $\mathrm{pH}$ shifts inside the porous carriers.

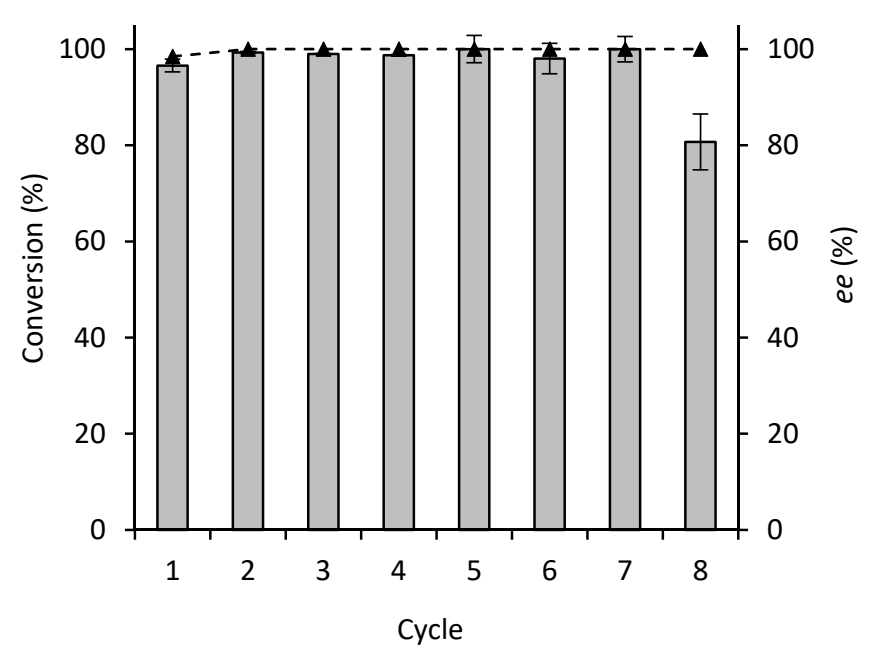

Figure 3. Recycling of wet AtHNL-EziG Opal $\left(10 \mathrm{U} \mathrm{mg}^{-1}\right)$ in eight successive cycles. Immobilization was performed by adsorption. Conversion (bars), enantiomeric excess (dotted line and triangles). Conditions: Ratio benzaldehyde:HCN in citrate/phosphate buffered MTBE, pH 5, 1:4, benzaldehyde (100 $\mu \mathrm{L}, 1 \mathrm{mmol}), 2 \mathrm{~mL} \mathrm{HCN}$ solution in citrate/phosphate buffered MTBE (1.5-2 M) pH 5, $27.5 \mu \mathrm{L}$ (0.1 mmol) 1,3,5-triisopropylbenzene as I.S. and a teabag filled with AtHNL immobilized on $60 \mathrm{mg}$ EziG Opal. Mol ratio of monomeric $A t \mathrm{HNL}: \mathrm{Fe}^{3+}$ was 1:5. The reaction was stirred at $900 \mathrm{rpm}$ at room temperature. The enzyme was washed for $1 \mathrm{~min}$ with $100 \mathrm{mM}$ citrate/phosphate buffer saturated MTBE pH 5 after each cycle. Reaction time: $1 \mathrm{~h}$. Error bars correspond to the standard deviation of duplicates $(n=2)$.

\subsection{Continuous Flow Reactions}

Immobilization enables the use of enzyme catalyzed synthesis reactions in continuous flow. Several advantages have been reported for this approach such as increased productivity, enhanced stability, reduced enzyme inhibition and easier downstream processing [26,36,37]. In addition, the reduced risk of manipulation of hazardous reagents, such as hydrogen cyanide, due to the smaller reaction volume used for the biocatalytic reactions is advantageous [28].

AtHNL was immobilized on EziG Opal in accordance with the optimized method (adsorption + wet AtHNL-EziG Opal) developed for batch reactions and tested in a continuous flow reactor (CFR). Figure 4 shows the synthesis of $(R)$-mandelonitrile at different flow rates. Near complete conversion and excellent enantioselectivity were achieved at $0.1 \mathrm{~mL} \mathrm{~min}^{-1}$. An important decrease in enantioselectivity was observed at flow rates above $0.2 \mathrm{~mL} \mathrm{~min}^{-1}$ suggesting that AtHNL on EziG Opal suffers from the competing chemical background reaction catalyzed by the carrier. Indeed, the reduced enantioselectivity could be explained as the result of the carrier catalyzed chemical reaction (Figure S3). Water content and $\mathrm{pH}$ had a major impact on the synthesis of rac-mandelonitrile. Pure EziG Opal formed circa $5 \%$ of rac-mandelonitrile due to the chemical background reaction whereas the addition of $306 \mu \mathrm{L}$ of phosphate buffer $\mathrm{pH} 5$ (same volume used for the enzyme immobilization) increased its formation up to $26 \%$ at $0.1 \mathrm{~mL} \mathrm{~min}^{-1}$ (Figure S3). 


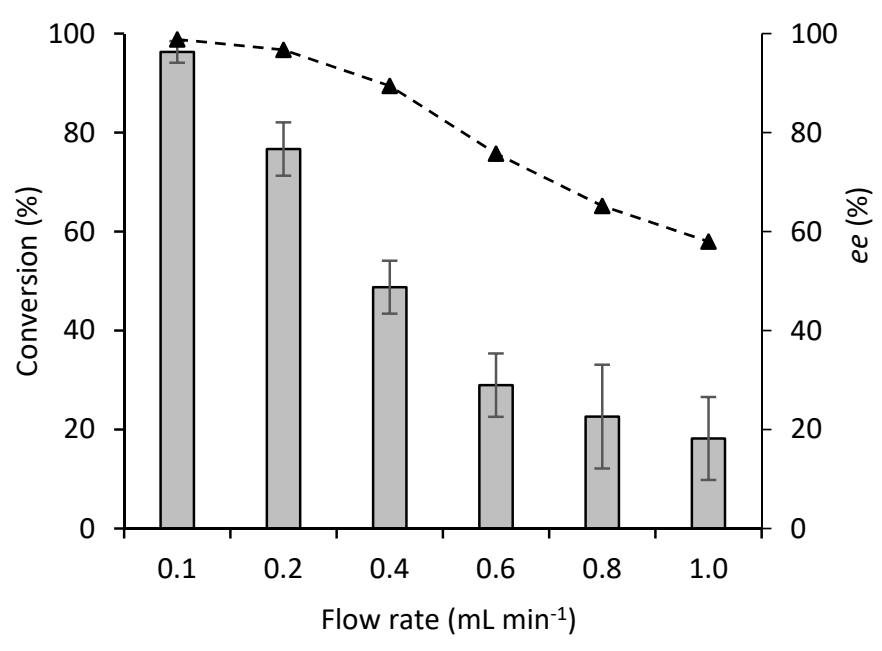

Figure 4. Synthesis of (R)-mandelonitrile using wet AtHNL-EziG Opal $\left(10 \mathrm{U} \mathrm{mg}^{-1}\right)$ in a CFR. Immobilization was performed by adsorption. Conversion (bars), enantiomeric excess (dotted line and triangles). Conditions: benzaldehyde (0.5 M), HCN solution in citrate/phosphate buffered MTBE (1.5-2 M) pH 5, 1,3,5-triisopropylbenzene (50 mM, I.S.), a CFR with AtHNL immobilized on $150 \mathrm{mg}$ EziG Opal. Mol ratio of monomeric AtHNL:Fe ${ }^{3+}$ was 1:4. Reactions were performed at room temperature. Error bars correspond to the standard deviation of triplicates $(n=3)$.

The stability of $A t \mathrm{HNL}$-EziG Opal was evaluated in the synthesis of $(R)$-mandelonitrile at

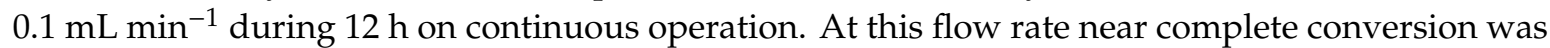
achieved with a mol ratio of monomeric $A t \mathrm{HNL}: \mathrm{Fe}^{3+}$ of 1:4, thus the robustness of the reaction system could be evaluated. Overall, AtHNL-EziG Opal displayed good conversion and high enantioselectivity during the stability study (Figure 5). Conversion of $74 \%$ and enantioselectivity of $89 \%$ respectively were achieved after $12 \mathrm{~h}$ of continuous operation. The decreased conversion and enantioselectivity after $12 \mathrm{~h}$ might be explained by enzyme deactivation due to the low $\mathrm{pH} 5$ and the chemical reaction catalyzed by the carrier.

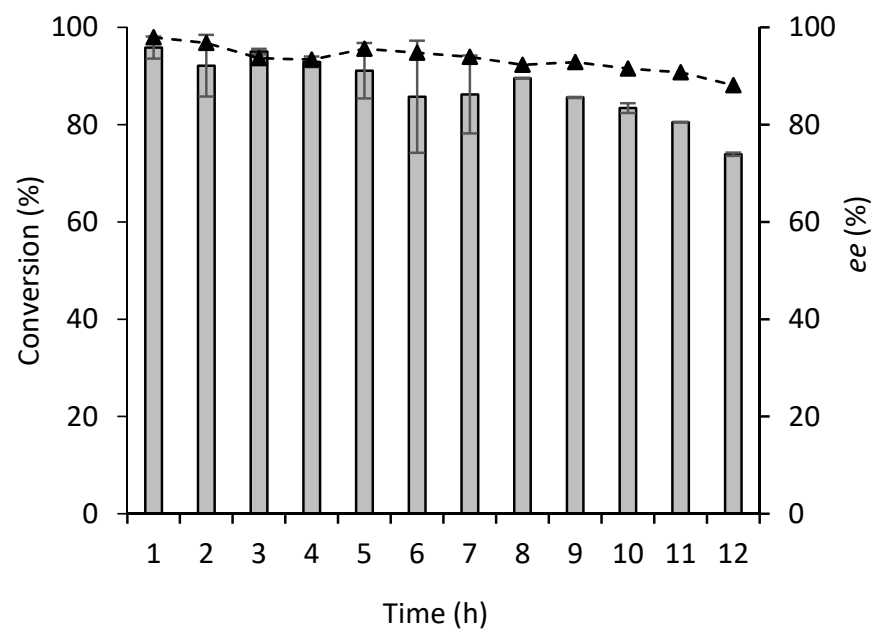

Figure 5. Stability of wet AtHNL-EziG Opal $\left(10 \mathrm{U} \mathrm{mg}^{-1}\right)$ in continuous flow at $0.1 \mathrm{~mL} \mathrm{~min}^{-1}$. Immobilization was performed by adsorption. Conversion (bars), enantiomeric excess (dotted line and triangles). Conditions: benzaldehyde (0.5 M), HCN solution in citrate/phosphate buffered MTBE (1.5-2 M) pH 5, 1,3,5-triisopropylbenzene (50 mM, I.S.), a CFR with AtHNL immobilized on $150 \mathrm{mg}$ EziG Opal. Mol ratio of monomeric $A t \mathrm{HNL}: \mathrm{Fe}^{3+}$ was 1:4. Reactions were performed at room temperature. Error bars correspond to the standard deviation of duplicates $(n=2)$ during the first $7 \mathrm{~h}$. From hour 8 , error bars correspond to the standard deviation of duplicates $(n=2)$ HPLC samples of the single experiment. 


\subsection{Comparison between Batch and Continuous Flow Systems}

The comparison of the performance of the batch and continuous flow systems cannot be made based on conversions due to the different set ups used. To establish a clear comparison regarding the performance of AtHNL-EziG Opal in batch and continuous flow, the specific rate and space-time-yield (STY) at a similar level of conversion were calculated.

The specific rate at $0.1 \mathrm{~mL} \mathrm{~min}^{-1}$ (96\% of conversion) was $0.26 \mathrm{~mol} \mathrm{~h}^{-1} \mathrm{genzyme}^{-1}$, surprisingly, it is half of the specific rate calculated in batch. At $0.4 \mathrm{~mL} \mathrm{~min}^{-1}$, a similar rate $\left(0.53 \mathrm{~mol} \mathrm{~h}^{-1} \mathrm{genzyme}^{-1}\right)$ was observed as compared to the batch system. However, the reduced conversion (49\%) might make downstream processing more problematic. Higher flow rates did not further improve the specific rate. AtHNL-EziG Opal in batch displayed higher specific rate $\left(0.51 \mathrm{~mol} \mathrm{~h}^{-1} \mathrm{~g}_{\text {enzyme }}{ }^{-1}\right)$ compared to AtHNL-Celite [15] $\left(0.20 \mathrm{~mol} \mathrm{~h}^{-1} \mathrm{~g}_{\text {enzyme }}{ }^{-1}\right)$ at $96 \%$ of conversion. In both cases the reported conversion was achieved after $30 \mathrm{~min}$ reaction time.

Previously, AtHNL was immobilized on Celite R-633 [19] and tested for the synthesis of $(R)$-mandelonitrile, the reaction in flow using a packed bed reactor did not enhance the rate of the reaction as compared to the batch system; the best specific rate calculated for the continuous flow system was $0.04 \mathrm{~mol} \mathrm{~h}^{-1} \mathrm{~g}_{\text {enzyme }}{ }^{-1}$ at $0.04 \mathrm{~mL} \mathrm{~min}^{-1}$ (85\% of conversion), whereas the batch system showed $0.07 \mathrm{~mol} \mathrm{~h}^{-1} \mathrm{~g}_{\text {enzyme }}{ }^{-1}$ (circa $91 \%$ of conversion). These results are circa six and seven-fold lower as compared to the best specific rate in flow $(0.1 \mathrm{~mL})$ and batch respectively reported in this study. In another study [17], the continuous flow synthesis of (S)-mandelonitrile with immobilized $\mathrm{HbHNL}$ on a siliceous monolith microreactor was 8 times faster as compared to the batch system and displayed a specific rate of $0.50 \mathrm{mmol} \mathrm{min}^{-1} \mathrm{genzyme}^{-1}$ at circa $95 \%$ conversion and $0.2 \mathrm{~mL} \mathrm{~min}{ }^{-1}$. This result is twice the specific rate observed for AtHNL-EziG Opal at a similar level of conversion and might be explained by diffusion limitation due to the partial blockage of the pores of EziG Opal during the enzyme immobilization by adsorption. The irregular structure of the microchannels and mesopores found in monolith microreactors overcome this limitation.

The space-time-yield (STY) is a parameter commonly used to compare the productivity of reactors with different size. Batch systems often require rapid stirring to reduce mass transfer limitations that may shorten the lifetime of the immobilized enzyme. On the other hand, stirring is not required in flow, thus this problem is avoided, and better productivities can be achieved $[17,25,29]$. Indeed, the AtHNL on EziG Opal catalyzed synthesis of $(R)$-mandelonitrile in flow displayed a STY of 690 mol $_{\text {product }} \mathrm{h}^{-1}$ $\mathrm{L}^{-1}$ genzyme $^{-1}$, whereas the batch approach led to only $187 \mathrm{~mol}_{\text {product }} \mathrm{h}^{-1} \mathrm{~L}^{-1} \mathrm{~g}_{\text {enzyme }}{ }^{-1}$ showing that the flow system greatly enhanced productivity. In batch, a similar productivity has been achieved previously with AtHNL-Celite $\left(150 \mathrm{~mol}_{\text {product }} \mathrm{h}^{-1} \mathrm{~L}^{-1} \mathrm{~g}_{\text {enzyme }}{ }^{-1}\right)$ [15].

Comparing the results for $A t \mathrm{HNL}$ of this study with the literature reports again demonstrates the advantages of flow chemistry. The synthesis of $(S)$-mandelonitrile in a siliceous monolith microreactor using either Hevea brasiliensis HNL (11.3 mg total protein; $1120 \mathrm{U}$ per monolith) or Manihot esculenta HNL (17.4 mg total protein; $1310 \mathrm{U}$ per monolith) showed STYs of 555 and $405 \mathrm{~mol}_{\text {product }} \mathrm{h}^{-1} \mathrm{~L}^{-1} \mathrm{genzyme}^{-1}$ [17]. Recently, a $\omega$-transaminase from Arthrobacter sp. (AsR- $\omega \mathrm{TA}$ ) was immobilized on EziG Amber (semi-hydrophobic carrier) for the kinetic resolution of $r a c-\alpha$-methylbenzylamine (rac- $\alpha$-MBA) [20]. The enzyme was shown to be highly stable on this carrier and was able to perform the kinetic resolution of rac- $\alpha$-MBA during 96 consecutive hours with excellent enantioselectivity ( $49 \%$ conversion and $99 \%$ ee). This flow system achieved a space time yield of $184 \mathrm{~mol}_{\text {product }} \mathrm{h}^{-1} \mathrm{~L}^{-1} \mathrm{genzyme}^{-1}$. The productivities reported in this study are comparable with the productivities reported for immobilized HNLs on siliceous carriers and other enzymes on EziG carriers.

\section{Materials and Methods}

\subsection{Chemicals}

Except when reported otherwise all chemicals were bought from Sigma Aldrich (Schnelldorf, Germany). Isopropanol and heptane were of HPLC grade ( $\geq 99 \%)$ and used as HPLC solvents. 
1,3,5-triisopropylbenzene (97\%) was from Fluka Chemie (Buchs, Switzerland). Potassium cyanide (KCN, 97\%) from J.T. Baker (Deventer, The Netherlands) was used as cyanide source in the HCN solution. ( \pm )-Mandelonitrile from Acros Organics (Geel, Belgium) was purified by flash chromatography (PE/MTBE 9:1/3:7).

\subsection{Heterologous Expression of Arabidopsis Thaliana HNL (AtHNL)}

pET28a-AtHNL expression plasmid containing the AtHNL gene (GenBank accession number AAN13041, EC:4.1.2.10) codon optimized for E. coli and with a polyhistidine tag ( His $_{6}$-tag) (see Table S1) was obtained from the group of Martina Pohl (Institute of Bio-and Geosciences, Jülich, Germany). E. coli BL21(DE3) was transformed with the expression plasmid for the production of the His-tagged AtHNL. A preculture was prepared by inoculating one single colony of E. coli BL21(DE3)-pET28aAtHNL in $10 \mathrm{~mL}$ of Lysogeny Broth (LB) medium with kanamycin $\left(40 \mu \mathrm{g} \mathrm{mL}^{-1}\right)$ and incubated overnight (Eppendorf/New Brunswick Scientific Incubator Shaker Excella E24 Series, Nijmegen, The Netherlands) at $37^{\circ} \mathrm{C}, 180 \mathrm{rpm}$. Subsequently, this preculture was used for the inoculation of $1 \mathrm{~L}$ of Terrific Broth (TB) medium containing kanamycin $\left(40 \mu \mathrm{g} \mathrm{mL}{ }^{-1}\right)$ and incubated at $37^{\circ} \mathrm{C}, 120 \mathrm{rpm}$. When the $\mathrm{OD}_{600}$ reached $0.7-0.9$ the protein expression was induced by adding $1 \mathrm{~mL}$ of $0.1 \mathrm{M}$ isopropyl $\beta$-D-thiogalactoside (IPTG) per liter of culture ( $0.1 \mathrm{mM}$ IPTG final concentration) and cultivation was continued at $25^{\circ} \mathrm{C}$, $180 \mathrm{rpm}$ for $20 \mathrm{~h}$.

Cells were harvested by centrifugation at $4{ }^{\circ} \mathrm{C}, 3600 \times g$ rpm during $20 \mathrm{~min}$ (Sorvall RC6, Thermo Fisher Scientific, Landsmeer, The Netherlands). The supernatant was discarded and the pellets were washed with $30 \mathrm{~mL}$ of $10 \mathrm{mM}$ sodium phosphate buffer $\mathrm{pH}$ 7, frozen in liquid nitrogen and stored at $-80^{\circ} \mathrm{C}$.

\subsection{Enzyme Purification}

The pellets containing AtHNL were resuspended in lysis buffer $(10 \mathrm{mM}$ potassium phosphate buffer pH 7.4 + DNase) and lysed in a cell disruptor (Constant Systems Ltd., Daventry, United Kingdom) at $1.5 \mathrm{kBar}$ and $4{ }^{\circ} \mathrm{C}$ to avoid protein denaturation. The cell free extracts were collected by centrifugation at $48,000 \times g, 1 \mathrm{~h}, 4^{\circ} \mathrm{C}$ (Sorvall RC6, Thermo Fisher Scientific, Landsmeer, The Netherlands). The enzyme was purified by using a NGC Chromatography system (Bio-Rad, Veenendaal, The Netherlands) by immobilized metal ion chromatography (IMAC) with chelating $\mathrm{Ni}^{2+}$ Sepharose (HiTrap Chelating HP $5 \mathrm{~mL}$, GE Healthcare) according to the manufacturer [38]. $20 \mathrm{mM}$ sodium phosphate $+0.5 \mathrm{M} \mathrm{NaCl}+$ $20 \mathrm{mM}$ imidazole $\mathrm{pH} 7.4$ was used for the enzyme binding and $20 \mathrm{mM}$ sodium phosphate $+0.5 \mathrm{M}$ $\mathrm{NaCl}+0.5 \mathrm{M}$ imidazole $\mathrm{pH} 7.4$ was used for the enzyme elution.

The purified AtHNL was concentrated with a $10 \mathrm{kDa}$ MWCO Amicon filter (Millipore, Amsterdam-Zuidoost, The Netherlands) and desalted with a PD-10 desalting column (Cytiva, Medemblik, The Netherlands) according to the supplier instructions [39].

\subsection{Enzymatic Activity Aassay}

AtHNL activity was determined spectrophotometrically (Agilent Technologies Cary 60 UV-VIS, Amstelveen, The Netherlands) according to the literature [15] with slight modifications. The cleavage of rac-mandelonitrile into benzaldehyde and hydrogen cyanide was followed at $280 \mathrm{~nm}$ and $25^{\circ} \mathrm{C}$ in $1 \mathrm{~cm}$ quartz glass cuvettes. Briefly, $1400 \mu \mathrm{L}$ of $50 \mathrm{mM}$ citrate/phosphate buffer $\mathrm{pH} 5$ and $200 \mu \mathrm{L}$ of enzyme solution (in $5 \mathrm{mM}$ phosphate buffer $\mathrm{pH} 6.5$ ) were mixed and incubated for $30 \mathrm{~s}$ at $25^{\circ} \mathrm{C}$. The reaction was started by adding $400 \mu \mathrm{L}$ of $60 \mathrm{mM}$ rac-mandelonitrile solution $(80 \mu \mathrm{L}$ of rac-mandelonitrile in $10 \mathrm{~mL} 3 \mathrm{mM}$ citrate/phosphate buffer, $\mathrm{pH} 3.5)$. The enzymatic activity was calculated with the molar extinction coefficient of benzaldehyde $\left(\varepsilon_{280}=1.376 \mathrm{mM}^{-1} \mathrm{~cm}^{-1}\right)$ and the background reaction (performed without enzyme) was subtracted in the final calculation.

One unit of $A t \mathrm{HNL}$ activity is the amount of micromoles of rac-mandelonitrile converted per minute in citrate/phosphate buffer $\mathrm{pH} 5$ at $25^{\circ} \mathrm{C}$. 


\subsection{Synthesis of Hydrogen Cyanide (HCN) Solution in MTBE}

A HCN solution in MTBE was made according to earlier studies [15-19,29]. $25 \mathrm{~mL}$ MTBE and $10 \mathrm{~mL}$ MilliQ water were mixed in a $100 \mathrm{~mL}$ Erlenmeyer and kept at $0{ }^{\circ} \mathrm{C} .0 .1$ mol potassium cyanide $(6.51 \mathrm{~g})$ was dissolved in the mixture and magnetically stirred for $15 \mathrm{~min} .10 \mathrm{~mL}$ of $30 \%(v / v) \mathrm{HCl}$ solution was added slowly and stirring was continued for $2 \mathrm{~min}$. The HCN solution was allowed to reach room temperature (circa $20^{\circ} \mathrm{C}$ ). The organic and aqueous phases were separated using a separation funnel and the organic layer containing $\mathrm{HCN}$ was collected. The separation was performed twice more after adding $7 \mathrm{~mL}$ of MTBE each time. Finally, $5 \mathrm{~mL}$ of $50 \mathrm{mM}$ citrate/phosphate buffer $\mathrm{pH}$ 5 was added to the organic fraction collected and it was stored in a dark bottle at $4{ }^{\circ} \mathrm{C}$.

The HCN concentration was determined in accordance to the literature [40]. $1 \mathrm{~mL}$ of $\mathrm{HCN}$ solution was added to $5 \mathrm{~mL}$ of $2 \mathrm{M} \mathrm{NaOH}$ in a $25 \mathrm{~mL}$ Erlenmeyer. The mixture was stirred for $2 \mathrm{~min}$. Potassium chromate was added as indicator. The solution was titrated with $0.1 \mathrm{M}$ silver nitrate. The cyanide reacts 1:1 with the silver and precipitates.

\subsection{Immobilization of AtHNL on EziG Opal by Adsorption}

The immobilization of AtHNL on EziG Opal by adsorption was performed as described previously [16,18,29]. Given volumes of AtHNL solution were concentrated in Amicon filters with a $10 \mathrm{kDa}$ MW cut-off, and subsequently added dropwise to $60 \mathrm{mg}$ of EziG Opal (batch) or $150 \mathrm{mg}$ of EziG Opal (flow). For batch reactions, AtHNL-EziG Opal was tightly packed in a regular paper tea bag $[16,29]$ and either directly used for biocatalytic reactions or dried $16 \mathrm{~h}$ under vacuum in a desiccator over silica gel before packing. A magnetic stirrer was attached to the tea bags as reported earlier $[16,29]$ to ensure tight packing and rapid stirring without mechanical attrition of the carrier. Reactions in flow were performed with wet AtHNL-EziG Opal (without drying and packing). The ratio of enzyme solution to carrier ( $\mu \mathrm{L}: \mathrm{mg}$ ) was 2:1 in all cases to ensure that the enzyme solution was completely absorbed by the carrier. The immobilization of different enzyme units was achieved by determining the enzyme activity and adjusting the amount of enzyme solution before its concentration.

\subsection{Immobilization of AtHNL on EziG Opal by Incubation}

The immobilization of $A t \mathrm{HNL}$ on EziG Opal by incubation was performed according to the manufacturer (see the instruction manual in the supplementary information). $2 \mathrm{~mL}$ of enzyme solution with the required units to be immobilized was incubated with $60 \mathrm{mg}$ of carrier in an orbital shaker (model RM:2M) at $30 \mathrm{rpm}$ during $2 \mathrm{~h}$ at room temperature. The binding of the enzyme to the carrier was monitored by determining the protein concentration of the supernatant after immobilization using the BCA protein determination (Pierce BCA protein assay kit, Thermo Fisher Scientific, Landsmeer, The Netherlands) in accordance with the manufacturer instructions [41].

\subsection{Synthesis of (R)-Mandelonitrile in Batch}

Several $(R)$-mandelonitrile syntheses were performed with $60 \mathrm{mg}$ of immobilized AtHNL-EziG Opal. The reaction conditions were as follows: $100 \mu \mathrm{L}$ benzaldehyde $(1 \mathrm{mmol}), 27.5 \mu \mathrm{L}$ 1,3,5triisopropylbenzene (internal standard (I.S.)), $2 \mathrm{~mL} \mathrm{HCN}$ in $50 \mathrm{mM}$ citrate/phosphate buffered MTBE pH 5 (1.5-2 M), tea bag filled with $60 \mathrm{mg}$ immobilized enzyme, $900 \mathrm{rpm}$ and room temperature. The ratio benzaldehyde to $\mathrm{HCN}$ solution was 1:4. The mole ratio $A t \mathrm{HNL}: \mathrm{Fe}^{3+}$ was 1:5.

\subsection{Enzyme Recyclability in Batch}

The enzyme recyclability was determined by several cycles of $(R)$-mandelonitrile synthesis according to $[15,16,18,29]$. The reaction conditions were as follows: benzaldehyde (100 $\mu \mathrm{L}, 1 \mathrm{mmol})$, $27.5 \mu \mathrm{L}$ 1,3,5-triisopropylbenzene (I.S.), $2 \mathrm{~mL} \mathrm{HCN}$ in $50 \mathrm{mM}$ citrate/phosphate buffered MTBE pH 5 (1.5-2 M), tea bag filled with $60 \mathrm{mg}$ immobilized enzyme, $900 \mathrm{rpm}$ and room temperature. The ratio benzaldehyde to $\mathrm{HCN}$ solution was 1:4. The mol ratio $A t \mathrm{HNL}: \mathrm{Fe}^{3+}$ was 1:5. Between each cycle the 
immobilized enzyme was washed for 1 min with $50 \mathrm{mM}$ citrate/phosphate buffered MTBE, pH 5, and stored at $4{ }^{\circ} \mathrm{C}$ in fresh citrate/phosphate buffered MTBE, $\mathrm{pH} 5$.

\subsection{Synthesis of (R)-Mandelonitrile in Continuous Flow}

One milliliter stainless steel flow reactor $(6.4 \mathrm{~cm}$ length, $0.45 \mathrm{~cm}$ inner diameter) was used for the continuous synthesis of $(R)$-mandelonitrile with $150 \mathrm{mg}$ of immobilized AtHNL on EziG Opal $\left(10 \mathrm{U} \mathrm{mg}^{-1}\right)$. The reactor was filled with $100 \mathrm{mg}$ of non-porous glass beads ( $1 \mathrm{~mm}$ diameter) and $150 \mathrm{mg}$ of EziG Opal containing immobilized enzyme (final reaction volume $=0.3 \mathrm{~mL}$ ). $10 \mathrm{~cm}$ of polytetrafluoroethylene (PTFE) tubing with $1.5 \mathrm{~mm}$ inner diameter was used to connect a syringe pump (Knauer, Germany) with the reactor. Initial conditions were as follows: $0.5 \mathrm{M}$ benzaldehyde, 1.5-2 M HCN in $100 \mathrm{mM}$ citrate/phosphate buffered MTBE, pH 5 and $50 \mathrm{mM}$ 1,3,5-triisopropylbenzene asI.S.. The synthesis of $(R)$-mandelonitrile was evaluated at different flow rates (from 0.1 to $1 \mathrm{~mL} \mathrm{~min}{ }^{-1}$ ) by chiral HPLC. The mole ratio AtHNL:Fe ${ }^{3+}$ was 1:4. The flow rate was checked at each sampling time by the difference of weight. Reactions were performed at room temperature. No significant pressure drop or increase was observed within the timeframe of the experiments.

\subsection{Enzyme Stability in Continuous Flow}

The stability of immobilized AtHNL on EziG Opal $\left(10 \mathrm{U} \mathrm{mg}^{-1}\right)$ was evaluated by performing a synthesis reaction during $12 \mathrm{~h}$ at $0.1 \mathrm{~mL} \mathrm{~min}^{-1}$ on stream at room temperature. The mol ratio At HNL: $\mathrm{Fe}^{3+}$ was $25 \%$. Samples were drawn at regular intervals and analyzed by chiral HPLC.

\subsection{Analysis}

Samples $(10 \mu \mathrm{L})$ were taken at different times during the reaction run and added to $990 \mu \mathrm{L}$ of heptane:2-propanol 95:5 in 1.5 mL Eppendorf tubes. A small amount of anhydrous magnesium sulphate $\left(\mathrm{MgSO}_{4}\right)$ was used to remove the water from the solution and the Eppendorf tubes were centrifuged at $13,000 \times g$ rpm for $1 \mathrm{~min} .850 \mu \mathrm{L}$ of the supernatant was transferred to a $4 \mathrm{~mL} \mathrm{HPLC}$ vial and $10 \mu \mathrm{L}$ was injected into the HPLC (Chiralpak AD-H column, column size: $0.46 \mathrm{~cm} \mathrm{I.D} \times 25 \mathrm{~cm}$ ). Heptane and 2-propanol were used as mobile phase with a flow rate of $1 \mathrm{~mL} \mathrm{~min}^{-1}$ and the UV detector was set at $216 \mathrm{~nm}$. The column temperature was set at $40^{\circ} \mathrm{C}$. The samples in the autosampler were maintained at $4{ }^{\circ} \mathrm{C}$.

\section{Conclusions}

AtHNL was successfully immobilized on EziG Opal by an optimized methodology. AtHNL-EziG Opal was recycled up to seven times in batch with nearly complete conversion and excellent enantioselectivity. The continuous flow system displayed excellent conversion and enantioselectivity at $0.1 \mathrm{~mL} \mathrm{~min}^{-1}$ and allowed to increase four times the productivity for the synthesis of $(R)$-mandelonitrile as compared to the batch system.

Supplementary Materials: The following information is available online at http://www.mdpi.com/2073-4344/10/ 8/899/s1, Figure S1: Leaching assay of AtHNL-EziG Opal, Figure S2: Blank reaction in batch, Figure S3: Blank reaction in flow, Figure S4. Recycling of AtHNL-EziG Opal $\left(20 \mathrm{U} \mathrm{mg}^{-1}\right)$ in eight successive cycles. Figure S5. HPLC detection of benzaldehyde and 1,3,5-triisopropylbenzene during $8 \mathrm{~h}$ of incubation, Table S1: AtHNL gene and Amino acid sequences.

Author Contributions: U.H. conceptualized and supervised the study; J.C., T.L. and M.A. performed the experiments; M.L. and P.B. developed the AtHNL overexpression and purification method; P.-L.H., L.G. and U.H. reviewed the manuscript and supervised the study. J.C. wrote and edited the manuscript. All authors have read and agreed to the published version of the manuscript.

Funding: This research was funded by the Secretary of Higher Education, Science, Technology and Innovation of Ecuador (Senescyt) and Universidad Laica Eloy Alfaro de Manabí (ULEAM) and by BE-BASIC, grant number FES-0905 to P.B. 
Acknowledgments: We thank Martina Pohl (Institute of Bio- and Geosciences-Jülich, Germany) for providing the pET28a-AtHNL expression plasmid. EnginZyme AB is also acknowledged for the kindly provision of EziG Opal used in this study. Mattia Lazzarotto is grateful to the European Commission and to the University of Trieste for an ERASMUS+ fellowship.

Conflicts of Interest: The authors declare no conflict of interest. The funders had no role in the design of the study; in the collection, analyses, or interpretation of data; in the writing of the manuscript, or in the decision to publish the results.

\section{References}

1. Dadashipour, M.; Asano, Y. Hydroxynitrile lyases: Insights into biochemistry, discovery, and engineering. ACS Catal. 2011, 1, 1121-1149. [CrossRef]

2. Steiner, K.; Glieder, A.; Gruber-Khadjawi, M. Cyanohydrin formation/Henry reaction. In Science of Synthesis: Biocatalysis in Organic Synthesis; Georg Thieme Verlag: Stuttgart, Germany, 2015; Volume 2, pp. 1-30.

3. Lanfranchi, E.; Steiner, K.; Glieder, A.; Hajnal, I.; Sheldon, R.A.; van Pelt, S.; Winkler, M. Mini-Review: Recent developments in hydroxynitrile lyases for industrial biotechnology. Recent Pat. Biotechnol. 2013, 7, 197-206. [CrossRef]

4. Bracco, P.; Busch, H.; von Langermann, J.; Hanefeld, U. Enantioselective synthesis of cyanohydrins catalysed by hydroxynitrile lyases-A review. Org. Biomol. Chem. 2016, 14, 6375-6389. [CrossRef]

5. Faber, K. Biotransformations in Organic Chemistry, 7th ed.; Springer Nature: Basel, Switzerland, 2018; pp. 224-233. [CrossRef]

6. Hanefeld, U. Immobilisation of hydroxynitrile lyases. Chem. Soc. Rev. 2013, 42, 6308-6321. [CrossRef]

7. Zhu, Y.; Chen, Q.; Shao, L.; Jia, Y.; Zhang, X. Microfluidic immobilized enzyme reactors for continuous biocatalysis. React. Chem. Eng. 2020, 5, 9-32. [CrossRef]

8. Cantone, S.; Ferrario, V.; Corici, L.; Ebert, C.; Fattor, D.; Spizzo, P.; Gardossi, L. Efficient immobilisation of industrial biocatalysts: Criteria and constraints for the selection of organic polymeric carriers and immobilisation methods. Chem. Soc. Rev. 2013, 42, 6262-6276. [CrossRef] [PubMed]

9. Liese, A.; Hilterhaus, L. Evaluation of immobilized enzymes for industrial applications. Chem. Soc. Rev. 2013, 42, 6236-6249. [CrossRef] [PubMed]

10. Hanefeld, U.; Gardossi, L.; Magner, E. Understanding enzyme immobilisation. Chem. Soc. Rev. 2009, 38, 453-468. [CrossRef] [PubMed]

11. Block, H.; Maertens, B.; Spriestersbach, A.; Brinker, N.; Kubicek, J.; Fabis, R.; Labahn, J.; Schäfer, F. Immobilized-Metal Affinity Chromatography (IMAC) in Methods in Enzymology; Academic Press: Cambridge, MA, USA, 2009; pp. 439-473. [CrossRef]

12. Das, K.K.; Reddy, R.C.; Bagoji, I.B.; Das, S.; Bagali, S.; Mullur, L.; Khodnapur, J.P.; Biradar, M.S. Primary concept of nickel toxicity-An overview. J. Basic Clin. Physiol. Pharmacol. 2018, 30, 141-152. [CrossRef] [PubMed]

13. Andexer, J.N.; Staunig, N.; Eggert, T.; Kratky, C.; Pohl, M.; Gruber, K. Hydroxynitrile lyases with $\alpha / \beta$-hydrolase fold: Two enzymes with almost identical 3D structures but opposite enantioselectivities and different reaction mechanisms. ChemBioChem 2012, 13, 1932-1939. [CrossRef] [PubMed]

14. Cassimjee, K.E.; Kadow, M.; Wikmark, Y.; Humble, M.S.; Rothstein, M.L.; Rothstein, D.M.; Bäckvall, J.-E. A general protein purification and immobilization method on controlled porosity glass: Biocatalytic applications. Chem. Commun. 2014, 50, 9134-9137. [CrossRef] [PubMed]

15. Okrob, D.; Paravidino, M.; Orru, R.V.A.; Wiechert, W.; Hanefeld, U.; Pohl, M. Hydroxynitrile lyase from Arabidopsis thaliana: Identification of reaction parameters for enantiopure cyanohydrin synthesis by pure and immobilized catalyst. Adv. Synth. Catal. 2011, 353, 2399-2408. [CrossRef]

16. Bracco, P.; Torrelo, G.; Noordam, S.; de Jong, G.; Hanefeld, U. Immobilization of Prunus amygdalus hydroxynitrile lyase on Celite. Catalysts 2018, 8, 287. [CrossRef]

17. van der Helm, M.P.; Bracco, P.; Busch, H.; Szymańska, K.; Jarzębski, A.; Hanefeld, U. Hydroxynitrile lyases covalently immobilized in continuous flow microreactors. Catal. Sci. Technol. 2019, 9, 1189-1200. [CrossRef]

18. Torrelo, G.; van Midden, N.; Stloukal, R.; Hanefeld, U. Immobilized hydroxynitrile lyase: A comparative study of recyclability. ChemCatChem 2014, 6, 1096-1102. [CrossRef] 
19. Brahma, A.; Musio, B.; Ismayilova, U.; Nikbin, N.; Kamptmann, S.; Siegert, P.; Jeromin, G.E.; Ley, S.V.; Pohl, M. An orthogonal biocatalytic approach for the safe generation and use of HCN in a multistep continuous preparation of chiral O-Acetylcyanohydrins. Synlett 2015, 27, 262-266. [CrossRef]

20. Böhmer, W.; Knaus, T.; Volkov, A.; Slot, T.K.; Shiju, N.R.; Cassimjee, K.E.; Mutti, F.G. Highly efficient production of chiral amines in batch and continuous flow by immobilized $\omega$-transaminases on controlled porosity glass metal-ion affinity carrier. J. Biotechnol. 2019, 291, 52-60. [CrossRef]

21. Tentori, F.; Bavaro, T.; Brenna, E.; Colombo, D.; Monti, D.; Semproli, R.; Ubiali, D. Immobilisation of old yellow enzymes via covalent or coordination bonds. Catalysts 2020, 10, 260. [CrossRef]

22. Aßmann, M.; Mügge, C.; Gaßmeyer, S.K.; Enoki, J.; Hilterhaus, L.; Kourist, R.; Liese, A.; Kara, S. Improvement of the process stability of Arylmalonate decarboxylase by immobilization for biocatalytic profen synthesis. Front. Microbiol. 2017, 8, 448. [CrossRef]

23. Yu, T.; Ding, Z.; Nie, W.; Jiao, J.; Zhang, H.; Zhang, Q.; Xue, C.; Duan, D.; Yamada, Y.M.A.; Li, P. Recent advances in continuous-flow enantioselective catalysis. Chem. Eur. J. 2020, 26, 5729-5747. [CrossRef]

24. Yoo, W.J.; Ishitani, H.; Saito, Y.; Laroche, B.; Kobayashi, S. Reworking organic synthesis for the modern age: Synthetic strategies based on continuous-flow addition and condensation reactions with heterogeneous catalysts. J. Org. Chem. 2020, 85, 5132-5145. [CrossRef] [PubMed]

25. Thompson, M.P.; Peñafiel, I.; Cosgrove, S.C.; Turner, N.J. Biocatalysis using immobilized enzymes in continuous flow for the synthesis of fine chemicals. Org. Process Res. Dev. 2019, 23, 9-18. [CrossRef]

26. Akwi, F.M.; Watts, P. Continuous flow chemistry: Where are we now? Recent applications, challenges and limitations. Chem. Commun. 2018, 54, 13894-13928. [CrossRef] [PubMed]

27. Sheldon, R.A.; Woodley, J.M. Role of biocatalysis in sustainable chemistry. Chem. Rev. 2018, 118, 801-838. [CrossRef]

28. Movsisyan, M.; Delbeke, E.I.P.; Berton, J.K.E.T.; Battilocchio, C.; Ley, S.V.; Stevens, C.V. Taming hazardous chemistry by continuous flow technology. Chem. Soc. Rev. 2016, 45, 4892-4928. [CrossRef]

29. Coloma, J.; Guiavarc'h, Y.; Hagedoorn, P.L.; Hanefeld, U. Probing batch and continuous flow reactions in organic solvents: Granulicella tundricola hydroxynitrile lyase (GtHNL). Catal. Sci. Technol. 2020, 10, 3613-3621. [CrossRef]

30. Vieille, C.; Zeikus, G.J. Hyperthermophilic enzymes: Sources, uses, and molecular mechanisms for thermostability. Microbiol. Mol. Biol. Rev. 2001, 65, 1-43. [CrossRef]

31. Guterl, J.K.; Andexer, J.N.; Sehl, T.; von Langermann, J.; Frindi-Wosch, I.; Rosenkranz, T.; Fitter, J.; Gruber, K.; Kragl, U.; Eggert, T.; et al. Uneven twins: Comparison of two enantiocomplementary hydroxynitrile lyases with $\alpha / \beta$-hydrolase fold. J. Biotechnol. 2009, 166-173. [CrossRef]

32. Paravidino, M.; Sorgedrager, M.J.; Orru, R.V.; Hanefeld, U. Activity and enantioselectivity of the hydroxynitrile lyase $\mathrm{MeHNL}$ in dry organic solvents. Chem. Eur. J. 2010, 16, 7596-7604. [CrossRef]

33. Effenberger, F.; Eichhorn, J.; Roos, J. Enzyme catalyzed addition of hydrocyanic acid to substituted pivalaldehydes-A novel synthesis of (R)-pantolactone. Tetrahedron Asymmetry 1995, 6, 271-282. [CrossRef]

34. Costes, D.; Wehtje, E.; Adlercreutz, P. Hydroxynitrile lyase-catalyzed synthesis of cyanohydrins in organic solvents: Parameters influencing activity and enantiospecificity. Enzym. Microb. Technol. 1999, 25, 384-391. [CrossRef]

35. Abdelraheem, E.M.M.; Busch, H.; Hanefeld, U.; Tonin, F. Biocatalysis explained: From pharmaceutical to bulk chemical production. React. Chem. Eng. 2019, 4, 1878-1894. [CrossRef]

36. Britton, J.; Majumdar, S.; Weiss, G.A. Continuous flow biocatalysis. Chem. Soc. Rev. 2018, 47, 5891-5918. [CrossRef] [PubMed]

37. Tamborini, L.; Fernandes, P.; Paradisi, F.; Molinari, F. Flow bioreactors as complementary tools for biocatalytic process intensification. Trends Biotechnol. 2018, 36, 73-88. [CrossRef]

38. Affinity Chromatography: Principles and Methods. Available online: www.sigmaaldrich.com/content/ dam/sigma-aldrich/docs/Sigma-Aldrich/General_Information/1/ge-affinity-chromatography.pdf (accessed on 14 October 2019).

39. PD-10 Desalting Columns. Available online: http://wwwuser.gwdg.de/ \{\}jgrossh/protocols/proteinpurification/PD10.pdf (accessed on 14 October 2019). 
40. Van Langen, L.M.; van Rantwijk, F.; Sheldon, R.A. Enzymatic hydrocyanation of a sterically hindered aldehyde. Optimization of a chemoenzymatic procedure for (R)-2-Chloromandelic Acid. Org. Process. Res. Dev. 2003, 7, 828-831. [CrossRef]

41. User Guide: Pierce BCA Protein Assay Kit. Available online: https://www.thermofisher.com/ document-connect/document-connect.html?url=https $\% 3 \mathrm{~A} \% 2 \mathrm{~F} \% 2 \mathrm{Fassets}$.thermofisher.com $\%$ 2FTFS-Assets\%2FLSG\%2Fmanuals\%2FMAN0011430_Pierce_BCA_Protein_Asy_UG.pdf\&title= VXNlciBHdWlkZTogUGllcmNIIEJDQSBQcm90ZWluIEFzc2F5IEtpdA (accessed on 15 October 2019). 